\title{
Effects of Advanced Producer Training and Technology on Cattle Mortality During Dystocia
}

\author{
Kimberly Inman \\ Department of Agriculture, Geosciences, and Natural Resources, University of Tennessee at \\ Martin, 256 Brehm Hall, Martin, TN, 38238, United States of America, USA \\ E-mail: kimdinma@ut.utm.edu \\ Clint Ary (Corresponding author) \\ Department of Agriculture, Geosciences, and Natural Resources, University of Tennessee at \\ Martin, 256 Brehm Hall, Martin, TN, 38238, United States of America, USA \\ E-mail: cary1@utm.edu
}

Will Bird

Department of Agriculture, Geosciences, and Natural Resources, University of Tennessee at Martin, 256 Brehm Hall, Martin, TN, 38238, United States of America, USA E-mail: wbird1@utm.edu

\section{Joey Mehlhorn}

Department of Agriculture, Geosciences, and Natural Resources, University of Tennessee at Martin, 256 Brehm Hall, Martin, TN, 38238, United States of America, USA

E-mail: mehlhorn@utm.edu

Jason Roberts

Department of Agriculture, Geosciences, and Natural Resources, University of Tennessee at Martin, 256 Brehm Hall, Martin, TN, 38238, United States of America, USA E-mail: jroberts@utm.edu

Received: August 5, 2020 doi:10.5296/jas.v8i4.17483
Accepted: Sep. 1, 2020

Published: Sep. 2, 2020

URL: https://doi.org/10.5296/jas.v8i4.17483 


\section{Abstract}

This study was conducted to investigate what variables may be more significant on farms in reducing both fetal and maternal mortality due to dystocia. Data on risk factors likely to impact cattle mortality were collected from a written herd questionnaire to determine farm management practices linked to cattle reproduction and the mortality related to dystocia. The questionnaire contained 16 questions grouped in the study. The survey contained qualitative and quantitative questions. The design utilized multiple data points with calving factors, age of dam, birth weight, sex of calf, breeds, heifers, cows, body condition, advanced beef producer training of recognition of impending labor, calf death, and dam death. Twenty-seven livestock producers from the state of Tennessee completed the questionnaire. The mean average herd size included 39 cows at reproductive age. The results showed labor detection technology and advanced training helped to reduce the herd mortality percentage. Cattle producers who place value on educating themselves and their workers can make their farms more efficient and profitable by making better on-farm decisions and implementing available technologies.

Keywords: dystocia, cattle, training, prediction, behavior

\section{Introduction}

Calving difficulty is technically called dystocia, which is a major cause of death in cow-calf cattle operations (Whittier, 2009). A difficult birth is any birth that requires some assistance. According to the National Agricultural Statistics (NASS) and the United States Department of Agriculture (USDA) there are over 500,000 cattle deaths every year during calving (USDA, 2011). Studies indicate that dystocia is responsible for over $33 \%$ of all calf losses (Whittier, 2009). There are many causes of dystocia but the most common is fetal oversize and prolonged calving (Schuenemann, 2012). Other common factors affecting dystocia are age of dam, sex of calf, dam's pelvic area size, fetomaternal disproportion, and the nutrition of the dam (Herring, 1996). Prevention of dystocia is a top priority in a cattle operation. Cattle loss due to dystocia impacts the operation financially through reduced number of cattle available to market as well as future losses in expanding breeding stock.

It is recommended that cows be observed three times daily and heifers four to five times daily to observe for signs of impending labor or difficulty (Hall, 2005). Past research has indicated that the dam's age has a profound effect on the incidence of dystocia (Newman et al., 1993). First-calf, 2-year-old heifers represent the greatest source of trouble to the beef herd owner. A first-time calving heifer needed assistance two times more than 3-year-old and older cows (Gregory et al., 1990). By the time the cow reaches 4 to 5 years of age, dystocia problems are minimal. There is a large economic impact on producers due to calf death, veterinary costs, and death of the cow (Whittier, 2009). Economic losses from death can be compounded in times when both input prices and live cattle prices are elevated. The double impact of lost revenue and added expenses create adverse risk conditions for producers. It is important for producers to focus on mitigating downside risk associated with calving as well as maintaining healthy breeding stock. If the cow goes into labor without awareness and there is difficulty it can become impossible for the cow to deliver the calf. 
Cattle labor is divided into three stages (Hall, 2005). Labor is initiated by the fetus. The three stages include the preparatory stage, the deliver stage, and the cleanup stage (McMillian, 2018). There are multiple changes that occur in the last 24 hours before calving (Saint-Dizier, 2015). If the producer has early awareness and knows the stages of labor, they can manage heifers and cows with dystocia and reduce mortality rates for the operation to be successful.

Recognizing the signs of imminent birth and the behavior of the heifer or cow before and during parturition is critical to know which needs birthing assistance. Usually, the first behavior noticed indicating immediate signs of labor will be occurring within 24 hours of calving is relaxation of the pelvic ligaments and strutting of the teats (Stuttgen, 2010). An important physical change to be aware of is udder development. A couple of months prior to calving, udder development is noticed in heifers. With a mature cow, udder development is usually noticed a couple weeks before delivery. The teats will start filling up and look full and distended. Another early indication is relaxing and swelling of the vulva or sometimes called springing. Also, be aware if you notice a cow not wanting to eat or is isolated from the herd (Stuttgen, 2010). There are other signs of impending labor even though they are not listed as a stage of parturition. Advanced training is essential for the farm management team to recognize labor symptoms or dystocia.

The following research objectives were generated to guide the study related to cattle dystocia and deaths of cattle:

1. Assess what producers are doing to manage the risk of cattle mortality and injury during birth on their operations.

2. Determine if previous education with emphasis on the recognition of early signs of impending labor in cattle will reduce the frequency of complications that result in injury or mortality therefore increasing profitability.

3. Establish what technology, such as video surveillance or devices, is being used to detect labor signs and symptoms on farms and how these types of continuous monitoring improve success rates.

\section{Method}

Data on risk factors likely to impact cattle mortality were collected from a pre-designed calving questionnaire (Appendix 1). The questionnaire was used to determine farm management practices linked to cattle reproduction and dystocia linked mortality. This was drafted and piloted with twenty-seven farm management producers to assess the questions via in person at The University of Tennessee at Knoxville cattle event. The questionnaire contained 16 questions consisting of both qualitative and quantitative questions. The design utilized multiple data points with calving factors, age of dam, birth weight, sex of calf, breeds, heifers, cows, body condition, advanced beef producer training of recognition of impending labor, calf death, and dam death. The topics were chosen based on management factors known to impact cow-calf mortality. 
The first page of the survey was an informed consent document that provided information on the survey objectives and the voluntary nature of the survey. Prior to its dispersion, the survey for this project was approved by the University of Tennessee at Martin Institutional Review Board (2019-706-E05-4005/Inman, Kim).

The study was conducted from August 2018 through November 2018 in and around Tennessee livestock farms. The mean average herd size was 39 females at reproductive age. The questionnaire compared farms with or without advanced trained active full-time onsite farm management and those using technology such as video or labor detection devices. The study is operationalized by reporting the breed on questionnaire and quantified by listing the breed. The study compares breeds on the farms then compares dystocia within certain breeds.

The dependent variables conducted were the level of training of the farm management, video surveillance of the cattle, and devices to detect impending labor. The farm management training variable was derived from the Master Beef Producer Course. Advanced farm management training was operationalized by an individual's farm having an increased level of recognition of impending labor signs and by the influence of training on response to signs of distress in cattle. The dependent variable was operationalized by participation in advanced learning such as Master Beef Producer Course and quantified by number of farms actively completing advanced learning. After this number was computed it was then compared to the farms with dystocia or mortality of cattle.

The dependent variable of the influence of video surveillance on cattle reproduction farms were operationalized by participation of camera technology and quantified by the number of farms with this technology. The total users of video technology were compared to dystocia and mortality of cattle in which the results of less mortality are significant.

The use of impending labor notification devices is a dependent variable operationalized by participation of the device and quantified by the number of farms using the devices. The total number of farms using the devices was computed and compared to farms with reported dystocia or cattle mortality.

The dam's age was studied and compared in relation to calving mortality. The variable was operationalized by the age of the dam. The questionnaire was quantified by a mean score of the age of dam.

The independent variables for this study were age of dam, birth weight, sex of calf, and breed.

\section{Results}

Data analysis consisted of t-tests and one-way ANOVA to analyze differences between groups, correlation tests to determine how variables are associated, and odds ratios to determine the association of certain management practices with calf survivability. Analysis Toolpak for Microsoft Excel was used to conduct all of the analysis. Differences were considered significant if $\mathrm{P}<0.05$.

A one-way between subjects ANOVA was conducted to compare the effects of producer education and use of labor monitoring technology on herd mortality for farms that had 
completed no advanced training and used no technology, farms only completing advanced training, farms completing advanced training and using technology, and farms just using technology. There was a statistically significant difference between groups as determined by one-way ANOVA at the $\mathrm{p}<0.05$ level for the four groups $[\mathrm{F}(3,23)=3.64, \mathrm{p}=0.027]$. A Tukey post hoc test revealed that the mean herd mortality percentage for the farms completing advanced training $(\mathrm{M}=1.21, \mathrm{SD}=1.36)$ was significantly different than the farms where no advanced training was completed and no technology was used $(\mathrm{M}=9.27, \mathrm{SD}=11.28)$.

A two-sample t-test assuming unequal variances was conducted to compare herd mortality percentage between farms completing advanced training using video technology and farms completing advanced training and not using video. There was a significant difference in the mortality percentages for farms completing advanced training using video technology $(\mathrm{M}=0$, $\mathrm{SD}=0)$ and farms completing advanced training and not using video $(\mathrm{M}=1.12, \mathrm{SD}=1.35) ; \mathrm{t}(12)$ $=-3.19, \mathrm{p}=0.008$.

A two-sample t-test assuming unequal variances found deaths were significantly lower where producers used labor detection devices compared to those that did not ( $\mathrm{p}=.0001)$; however, there is an insufficient number of active users to reliably conclude on this variable.

Calves and cows at farms that have completed advanced training compared to farms not completing advanced training or using technology have a $173 \%$ increase in the odds of living (odds ratio $=2.73 ; 95 \%$ confidence interval $[\mathrm{CI}]=1.00,1.04$ ). Calves and cows at farms using video compared to farms not completing advanced training or using technology have a $124 \%$ increase in the odds of living (odds ratio $=2.24 ; 95 \%$ confidence interval $[\mathrm{CI}]=0.99,1.04$ ).

Correlation tests determined that male calves were slightly more positively associated with dystocia than female calves, 0.63 and 0.57 respectively. First calf heifers were more positively associated with dystocia than mature cows, 0.65 and 0.39 respectively.

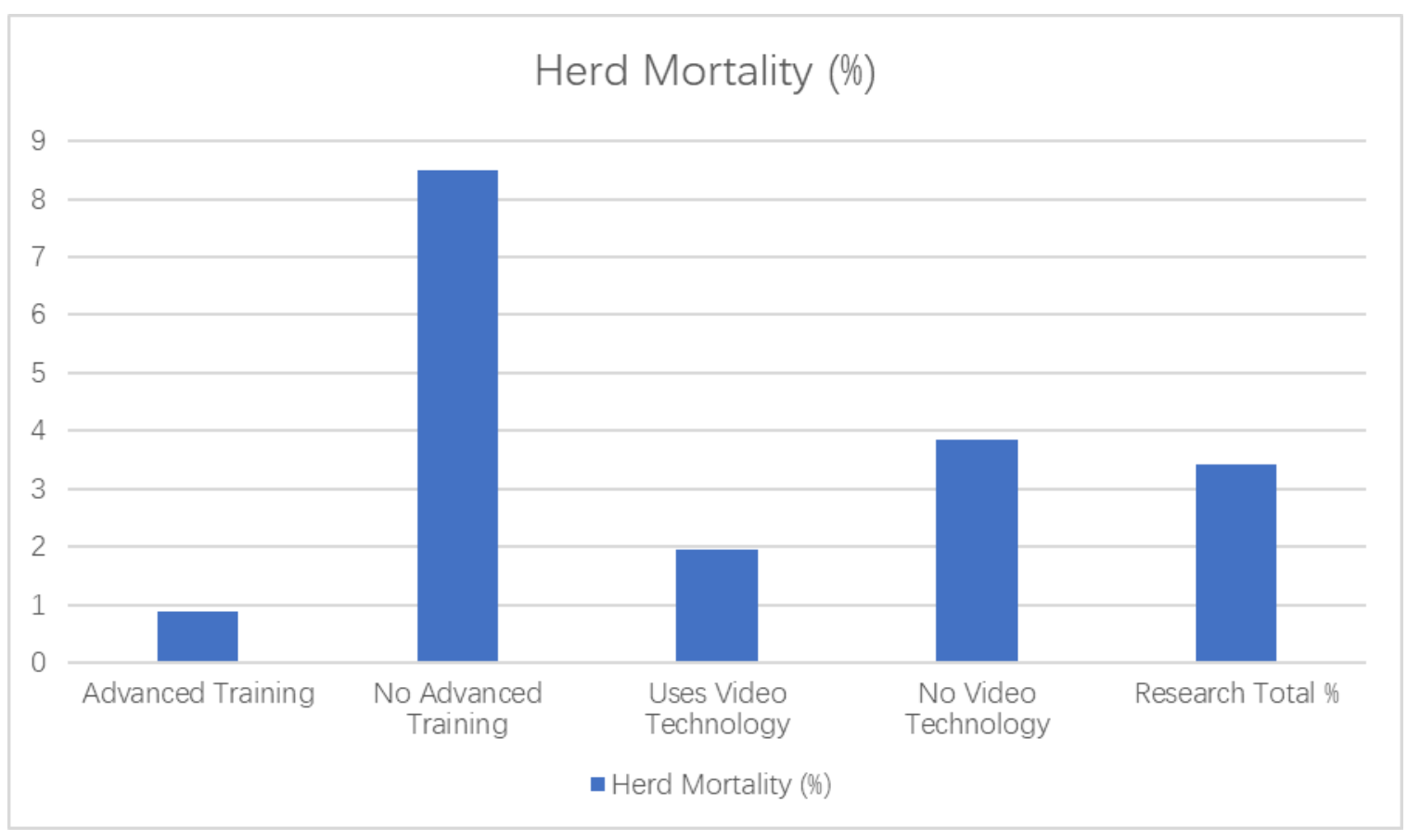


Figure 1. Average herd mortality percentage for producers incorporating labeled management techniques

It was determined there is a considerable herd mortality percentage decrease if the producer has completed an Advanced Master Beef Producer Course or uses video technology, 67 percent decrease and 43 percent decrease respectively, compared to the research total mortality of 3.42 percent but not statistically significant $(\mathrm{P}>0.05)$.

\section{Discussion}

The results of this study support the idea that educational programs for producers and available herd monitoring technologies can reduce herd mortality associated with dystocia. Video technology was found to be the most commonly used form of monitoring technology. Very few producers in this study had incorporated labor detection devices into their management.

The Advanced Master Beef Producer Program is an educational opportunity designed to provide research-based information to the beef producers of Tennessee in order for them to improve their profitability and competitiveness in the industry. This course provides in-depth information on topics such as reproduction, nutrition and forages, marketing, cattle behavior, and food safety. It is open to all producers including former graduates of the state's original Master Beef Producer series. Upon completion producers qualify to apply for financial assistance with the Tennessee Agricultural Enhancement Program. Over 23,000 certifications have been issued for the Master Beef Producer Program (UTBFC, 2020).

Technology is another valuable resource available to beef producers to help reduce losses associated with dystocia. Currently, multiple devices designed to recognize impending labor automatically are available on the market. Examples of devices in use include pedometers, accelerometers, tail mounted contraction sensors, inclinometers, and vaginal thermometers. Pedometers and accelerometers depend on changes in activity, such as time spent lying down or pacing, to help predict calving time. Tail mounted sensors detect tail contractions and their duration while inclinometers record the position of the tail. Vaginal thermometers detect a decrease in vaginal temperature and the expulsion of the allantochorion. These devices operate on the same principle; once the predictive sign is detected by a sensor placed on or in the cow, a radio wave signal is generated and forwarded to a receiver that analyses the data and sends voice or text messages via mobile communication to the farm management providing warning of impending calving (Saint-Dizier, 2015). These forms of technology are more costly for the producer and potentially not as familiar which might be reasons to explain why few producers in this study were actively using these forms of monitoring as part of their herd management. As with any production input, producers must weigh the cost against the potential return. The goal of a producer is to produce a live calf and retain a healthy cow that will be able to produce another calf in the future. It is recommended that producers review all aspects of technology before deciding on what is right for their operation. Repeating this study and including a larger number of farms that use labor detection devices would provide some better comparisons between groups. 
An excellent resource for better calving management is video cameras to monitor calving and signs of dystocia. In this study, video was the most widely used technology and did have a significant impact on reducing the percentage of herd mortality between producers who had received advanced training. Video surveillance monitoring systems help to make the daily task of monitoring cattle easier and makes remote areas more accessible. Advances in video surveillance have made the technology more feasible and affordable for producers. With the technology, especially wireless, the video feeds can be viewed from computers, smartphones, and electronic tablets (Smith, 2014). The video can be viewed on any Internet capable device, in any location, often used at home or work (Smith, 2014). An example of a negative aspect of video surveillance to detect dystocia and impending labor is loss of internet. The use of video surveillance devices might be limited by broadband issues that many rural producers face. It is not uncommon for many cattle producers in rural Tennessee are facing limited broadband access on their farms. While broadband Internet service has improved over the years in Tennessee, many producers are still reliant upon cell service or satellite for their Internet needs. As the state continues to expand broadband to rural areas, it is expected that this technology will be more widespread among producers in the future.

The results of this study indicate education and training are imperative to any producer wanting to stay competitive within their respective industry. A recent survey on the education attainment of the principal operators of all farms showed $41.5 \%$ completed high school, $24.9 \%$ completed some college, and $24.8 \%$ completed college (Hoppe, 2014). This lack of advanced education may mean producers rely mostly on education provided by agriculture extension services, cooperatives, or national, state, or local cattle organizations to help them improve their current management practices. Success in producer training has been seen with Beef Quality Assurance (BQA) training. 44.3\% and 21.6\% of producers recorded making changes in the selection of injection sites and antibiotic selection and use, respectively, after attending training (USDA, 2008). These types of training sessions generally allow adult learners to learn about best practices through traditional lecture-based sessions and experiential learning.

\section{Conclusion}

Dystocia and the associated losses can have a major economic impact on beef cattle producers. Producers must determine the most profitable input use for their operation. It is important to consider that each producer is different and faces different challenges with their operations. There is rarely a one size fits all approach to effective farm management. Each producer should understand their individual cost of production and have good data in order to make the right decision for their operation. Advanced training for farm management and continuous monitoring programs are essential to decrease the incidence of mortality and injuries in beef cattle. This study clearly shows the advantages of advanced education for producers on the management of cattle reproduction with strategies to reduce and early detect dystocia and its effects on calves is top priority for successful production even when monitoring technologies are in place. The use of video technology increases the monitoring of the cattle for distress and significantly reduces mortality and financial loss of the operation. However, newer technologies provide a predictive value allowing the producer to 
become aware of impending labor at least one hour before it begins. Video monitoring only allows for real-time viewing of the animals which could delay needed action.

There appears to be positive, synergistic effects when advanced training is combined with the technology available to cattle producers. We can say with confidence that agricultural enhancement programs designed to increase producers' knowledge are worth the effort and expense and technologies are making a difference in the welfare of animals.

Further studies could perform cost benefit analyses between different types of video systems used or between the various forms of technology. As technology continues to evolve and more producers have access to broadband Internet it is likely that the video tools will become a larger part of the producer's management toolbox. The use might also be increased as more producers adapt more to technology as a whole. The rise of cell phones and use of digital tools for our everyday life will impact how producers do business in the future. Investigations into the specific types of advanced training that producers have completed and the effects these had on their operations would be helpful in order to identify the most beneficial topics.

\section{References}

Gregory, K. E., Echternkamp, S. E., Dickerson, G.E., Cundiff, L.V., Koch, R.M., Van Vleck, L.D. (1990). Twinning in cattle: iii. effects of twinning on dystocia, reproductive traits, calf survival, calf growth and cow productivity.J. Anim. Sci., 68, 3133-3144. https://doi.org/10.2527/1990.68103133x

Hall, J. B. (2005). The Cow-Calf Manager. Virginia State University. [Online] Available: http://www.sites.ext.vt.edu/newsletter-archive/livestock/aps-05_03/aps-409.html

Herring, W. O. (1996). Calving Difficulty in Beef Cattle: BIF Fact Sheet. University of Missouri, Department of Animal Sciences. [Online] Available: https://extensiondata.missouri.edu/pub/pdf/agguides/ansci/g02035.pdf

Hoppe, R. A. (2014). Structure and Finances of U.S. Farms: Family Farm Report. 2014 ed. [Online] Available: https://www.ers.usda.gov/webdocs/publications/43913/50364_eib-132.pdf?v=1852

McMillian, K. (2018). Labor and Delivery; Three Stages of Calving. The Progressive Farmer, (1), 728 .

Newman, S., MacNeil, M. D., Reynolds, W. L., Knapp, B. W., \& Urick, J. J. (1993). Fixed effects in the formation of a composite line of beef cattle: i. experimental design and reproductive performance. J. Anim Sci., 71, 2026-2032. https://doi.org/10.2527/1993.7182026x

Saint-Dizier, M. (2015). Methods and on-farm devices to predict calving time in cattle. The Veterinary Journal, 3, 349-356. https://doi.org/10.1016/j.tvj1.2015.05.006

Schuenemann, G. (2012). Calving Management in Dairy Herds: Timing of Intervention and Stillbirth. College of Veterinary Medicine, VME-29,12 


\section{Macrothink}

Smith, T. (2014). Cattle and More on Camera. Angus Journal. 6 38-39. https://doi.org/10.22233/20412495.0314.38

Streyl, D., Sauter-Louis, C., Braunert, A., Lange, D., Weber, F., \& Zerbe, H. (2010). Establishment of a standard operating procedure for predicting the time of calving cattle. Journal of Veterinary Science, 12(2), 177-185. https://doi.org/10.4142/jvs.2011.12.2.177

Stuttgen, S. (2010). The 3 Stages of Bovine Parturition. University of Wisconsin Extension Beed Information Center.[Online] Available:https://fyi.extension.wisc.edu/wbic/files/2011/03/3-Stages-of-Parturition3.pdf

USDA National Animal Health Monitoring System. Beef 2007-08 part I: reference of beef cow-calf management practices in the United States, 2007-08. Fort Collins, Colo: USDA, 2008; 64.

USDA, (2011). Cattle Death Loss. National Agricultural Statistics Service. [Online] Available:https://downloads.usda.library.cornell.edu/usda-esmis/files/vh53wv75j/xp68kk00g/ v405sd14m/CattDeath-05-12-2011.pdf

UTBFC, (2020). Tennessee Master Beef Producer Program. University of Tennessee Institute of Agriculture. [Online] Available:http://utbfc.utk.edu/TMBP.html

Whittier, W., Dee, C., Nancy, M., Currin, J. F., \& Hall, J. B. (2009). Calving Emergencies In Beef Cattle: Identification and Prevention. Virginia Tech. VCE Pub.400-018. [Online] Available: http://pubs.ext.vt.edu/400/400-018/400-018.html

\section{Appendix 1}

Cattle Calving Mortality Survey

Please Select Correct One

1. Type of Herd:

Purebred: Commercial: Mixed:

2. Reproducing Herd size: $>60$ head, >50 head, >40 head, >30 head, >20 head

3. Number of Heifers calved in last 12 months

4. Number of Cows calved in last 12 months

5. Average Age of Dams at birth:

$>10$ years, $8-10$ years, 6- 8 years, 4-6 years, 3 years, 2 years 
6. Dam Breed:

7. Sire Breed:

8. Dam Body Condition score pre-calving: thin $(<3)$, good $(3-3.5)$, fat $(>3.5)$

9. How often cattle checked for signs of calving every:

24 hrs, 12 hrs, 6-12 hrs, 4-6 hrs, 2-4 hrs, 1-2 hrs, Continuous Monitor

10. Average calf birth weight

11. List number of Sex of calves:

Males Females

12. Completed producer trained such as Master Beef Producer Course: Yes or No

13. Uses video camera technology on farm:

Yes or No

14. Uses labor detection devices:

Yes or No

15. Number of cattle with dystocia episodes in last 12 months

16. Total calf or dam deaths in last 12 months during calving

Thank you for completing the survey!

\section{Copyright Disclaimer}

Copyright for this article is retained by the author(s), with first publication rights granted to the journal.

This is an open-access article distributed under the terms and conditions of the Creative Commons Attribution license (http://creativecommons.org/licenses/by/4.0/). 